\title{
Güncel Mimaride Yerel Malzemenin İzi
}

\author{
Edanur FETTAHOĞLU1 ${ }^{1}$, Şengül YALÇINKAYA ${ }^{1}$
}

Öz

Yakın geçmişte kültürlerarası etkileşimin ve iletişimin artması ile bölgesel unsurlar yerini küresel unsurlara bırakmaya başlamıştır. Mimari, bu değişimlerin belirgin olarak görülebildiği alanlardan biridir. Geçmişte yerel malzemeler, coğrafi koşullar ve kültürel özellikler ile şekillenen mimari yapılar, günümüzde seçeneklerin artması, teknolojinin gelişmesi, kültürel özelliklerde meydana gelen değişimler vb. ile farklılaşmış, dünya genelinde benzer bir dil oluşmuştur. Bunun yanında yerele özgü malzeme, yapım tekniği ve biçimlerinin tasarım anlayışı içinde yer aldığı örneklere rastlanmaktadır. Çalışma modern yapı tasarımında yerel malzeme kullanımı konu edinilmektedir. Araştırmada, öncelikle güncel mimarlık ortamında yerel malzemeye değinilmiş ve Peter Zumthor'a ait yerel malzeme ve tekniğin kullanıldığı 5 yapısı analiz edilmiştir. Yerel malzemenin sahip olduğu hafıza ve maneviyat özelliği onu mimari kimlik oluşturmada etkili bir öğe haline getirmekte ve çeşitli algısal deneyimlere imkân vermektedir. Yerel malzemenin bugünün tasarım düşüncesi ile buluşarak yeninden yorumlanması geleneksel ile moderni birleştirmekte, özgün ve kimlikli mimari ürünler ortaya çıkmaktadır.

Anahtar Kelimeler: Yerel Malzeme, Yerel Yapım Teknikleri, Doğal Malzeme, Mimari Yaklaşım, Peter Zumthor

\section{Traces of LocalMaterials in Contemporary Architecture}

\begin{abstract}
Regional elements are replaced by global ones due to the increase in intercultural interaction and communication in recent years. Architecture is an area where those changes are evident. The form and concept of architectural structures used to be based on local materials, geographical conditions, and cultural norms. However, today, architecture has adopted a common language worldwide due to the multitude of options, advances in technology, and changes in cultural characteristics. However, there are some architectural structures made of local materials and construction techniques. This paper focused on the use of local materials in modern building designs. This study first addressed local materials in the contemporary architectural environment and then analyzed Peter Zumthor's five buildings constructed with local materials and techniques. Local materials play an essential role in architectural identity because they have memory and spirituality. They also allow users to have a variety of perceptual experiences. Local materials undergo reinterpretation and meet the design perspective of today, combining traditional with modern and resulting in authentic architectural structures with a particular identity.
\end{abstract}

Keywords: Local Materials, Local Construction Techniques, Natural Materials, Architectural Approach, Peter Zumthor

\footnotetext{
${ }^{1}$ Karadeniz Teknik Üniversitesi, Mimarlık Fakültesi, İç Mimarlık Bölümü, Trabzon.

*ilgili yazar/Corresponding author: sengulyalcinkaya@ktu.edu.tr

Gönderim Tarihi / Received Date: 13.05.2021

Kabul Tarihi / Accepted Date: 26.08.2021
} 


\section{Giriş}

Mimari tasarım süreci birçok etkene ve değişkene bağlı olarak şekillenmektedir. Fiziksel, davranışsal ve kültürel faktörler farklı şekillerde ve boyutlarda mimari tasarım sürecini etkilemektedirler (Dönmez, 2006 s. 140). Mimari bir yapıda kimliğin izlerini yapım tekniğinden planına birçok unsurda görmek mümkündür. Bu unsurlar arasında yer alan malzeme de özellikle geleneksel yapılar incelendiğinde kimlik oluşumunda dikkat çeken bir kavram olarak karşımıza çıkmaktadır (Nooraddin, 2012, s. 95). Geçmişte malzeme tercihi, yapının inşa edildiği bölgede erişilebilir oluşu, dayanımı, bölgesel koşullara uyumu gibi sebepler ile gerçekleştirilirken günümüzde teknolojinin gelişmesi, yeni kaynakların ortaya çıkması ve mevcut malzemelerin geliştirilmesi gibi etkenler ile farklılaşmıştır (Yağı, 2019, s. 1). Bu farklılaşma mimari tasarım sürecini ve mimari yapıyı etkilemiştir.

Günümüzde yerel malzeme, geleneksel yapım tekniklerinin yanında güncel teknoloji ile birleştirilerek farklı şekillerde uygulanmaktadır. Bu durumdan yola çıkılarak yapılan çalışmada yerel malzemenin günümüz mimari yaklaşım ile birleşimi ile ortaya çıkan güncel yorumlar araştırılmıştır. Çalışmada yerel malzeme ve tekniği özgün mimari anlayışı ile buluşturan Peter Zumthor ait tasarımlar incelenerek, yerel malzeme ile ortaya konulan biricik, benzersiz örnekler analiz edilmiştir. Zumthor'un yerel malzemeyi ustaca kullanımı ile tasarımlarına birçok artı değer kazandırmıştır. Yerel malzemenin ve tekniklerin tasarımlarda yer almaya devam etmesi mimariye ait bilginin kaybolmaması ve yaşatılması sağlanmaktadır. Ayrıca bu durum yapının çevre ile uyumunu, özgün olmasını ve kimlik kazanmasını sağlarken, ekolojik ve sürdürülebilirlik başta olmak üzere çok yönlü kazanımları içermektedir.

\subsection{Güncel mimaride yerel malzeme kullanımı}

Malzeme tercihi ister doğal ister yapay malzeme olsun, mimari tasarım sürecinde geniş ölçekli kavramlardan küçük detaylara kadar birçok aşamada önemli bir rol üstlenmektedir. En ilkel yapılarda dahi malzeme mimari yapıtın önemli öğelerinden biri olmuş hem görsel hem de işlevsel olarak etki göstermiştir (Gezer, 2012, s. 98). Her geçen gün yeni bir malzeme ve yapım tekniği ile karşılaştığımız günümüzde malzemeye dair birçok farklılaşma gözlenmekte ve yapı üzerinde gözlenebilir bir etkisi olduğu da görülmektedir.

Güzer (2006, s. 38)'e göre modern zamanda malzeme seçeneklerin artması, malzemenin tasarım sürecindeki yerini değiştirmiştir. Tasarım sürecinde malzeme, sonradan eklenebilecek ve değiştirilebilecek bir girdiye dönüşmüştür. Bu durum bir taraftan "özgürlük" sağlarken, diğer taraftan yapıyı "özgün olma" ve "eser olma" özelliğinden uzaklaştırır. Kuma ise projelerde malzemenin yeni mimari dil geliştirmede temel odak noktası olduğunu vurgulamaktadır (URL-1, 2021). Har daim tasarım sürecinde belirleyici öğe olan malzemenin günümüz koşullarında etkisi şekil değiştirse de yapının oluşumunda sahip olduğu güç değişmemiştir.

Pamir' e göre mimaride iyi malzeme, farklı koşullarda yeni anlamlar ortaya çıkartabilen, duyulara hitap eden ve gizemli ama sizi kendi hakkında yanıltmayan malzemedir (2011,s.22-23). Tasarımın etkin gücü olan malzemede, bugün çeşitliliği çok artmıştır. Doğal malzemenin taklitleri veya farklı etkilere sahip yeni malzemelerle yapı eylemi için sınırsız seçenek sunmaktadır. Bu durum tasarımı ve tasarımcıyı farklı şekillerde etkilemektedir. Tasarımcıdan sunulan seçenekler arasından seçim yapması beklenirken, tasarım açısından ise doğal malzemenin sahip olduğu özelliklerin yapay malzeme tarafından taklit edilmesi ile yaratılmak istenen algının sınıflı kalmasına neden olmaktadır 
(Arpacıoğlu ve Kuruç 2010, s. 2-3). Genel olarak görsel konfor belli ölçülerde sağlanırken, malzemenin dokunsal ve işitsel özellikleri sınırlı yansıtılmaktadır. Algıyı uyaran öğelerin azalması, bireyin mekân ile kurduğu ilişkiyi zayıflatacaktır.

Mimaride kullanılan yapı malzemelerinin çeşitlenmesi ve farklılaşması mimari ile ilgili birçok kavram üzerindeki etkisinin de farklılaşması sonucunu doğurmuştur. Mimari kimlik ve algı da bu kavramlar arasında yer almaktadır. Bugün özellikle teknolojik gelişmelerin etkisiyle farklı malzemeler birlikte kullanılabilmekte, çeşitli işlemlerden geçirilerek farklı malzemeler üretilebilmekte hatta bir malzeme rahatılıkla başka bir malzemenin görsel özelliklerini taşıyabilmektedir. Bu ve benzeri durumlar malzemenin kullanımı, kullanıcı üzerindeki algısal etkisi gibi konularda çeşitli değişimlere sebep olmaktadır (Yıldız ve Seçkin, 2019, s. 6-7). Tüm bunların ışığında olumlu veya olumsuz etkileri ile malzeme tasarım sürecinde önemli bir unsur olarak karşımıza çıkmaktadır.

Günümüzde dünya genelinde malzeme seri üretime geçtiğinden aynı malzeme farklı bölgelerde kullanılabilmektedir. Birçok etkene bağlı olarak ortaya çıkan küreselleşme malzemeyi de evrenselleştirmiştir. Bu durum, yerel değerler ve geleneksel unsurların kaybolmasına neden olabilmektedir. Geleneksel yapılarda kullanılan malzemeler büyük çoğunlukla bölgede yer alan ve bölgenin coğrafi özellikleri ile uyumlu, ekonomik ve işlevsel olarak kullanıcıya olumlu katkıları olan malzemeler olmuştur (Schittich, 2003; Aktaran: Alaca Tınmaz, 2018, s. 27). Yerel malzeme kullanımı söz konusu katkılarının yanı sıra yapının inşa edildiği bölgeyi de temsil etmektedir. Bu sebeple yerel malzemenin yoğun olarak kullanıldığı geleneksel yapılar geleneksel doku oluşturmaktadırlar(Özgünler, 2017, s. 35). Yerel mimari ve geleneksel dokuya sahip yerler, mimari kimlik arayışı açısından ayrıcalıklı, özel bir yere sahip olarak görülmektedirler. Günümüzde ise güncel mimari içerisinde çeşitli amaçlarla yerel malzeme kullanımının tercih edildiği görülmektedir.

Dünya genelinde görülen yerel malzemeler toprak (kerpiç, tuğla), ağaç (kestane, bambu, saz vb.)ve taş (valzer kuvarsit, taş gabyonlar vb.) olarak üst başlıkta toplanabilir. Gelenekselde yerin özelliğine bağlı olarak türü ve uygulama tekniği değişebilmektedir. Bunlar içerisinde toprak esaslı malzemeler kırsal bölgeler başta olmak üzere birçok bölgede sıklıkla kullanılmaktadırlar. Yerel, ucuz ve kolay üretilebilme özelliklerine sahip olması; bunun yanı sıra ısı depolama gibi özellikleri toprak malzemenin tercih sebepleri arasındadır (Özgünler, 2017, s. 35). Toprak esaslı malzemeler arasında sıklıkla kullanılan kerpiç ve tuğlanın özellikleri benzerlik gösterir. Toprak malzemenin temel özelliklerini taşımalarının yanı sıra farklılıkları ise kerpicin enerji harcamadan güneş ışınları ile kurutulması, tuğlanın $900^{\circ} \mathrm{C}$ sıcaklığa sahip bir fırında pişirilmesidir. Ek olarak, tuğla basınç altında kalıplanıp şekillendirilmekte, kerpiç ise böyle bir işleme gerek duyulmaksızın, insan gücü ile kalıplara yerleştirilerek üretilmektedir (Çavuş vd., 2015, s. 185). Ayrıca uygulamada ise farklı estetik değerlere sahiptirler.

Güncel olarak yapılmış örneklere bakıldığında Senegal'in Fass Köyü'nde inşa edilen okulda mimar, yapı malzemesi olarak duvarlarda sıkıştııımış kerpiç tuğla kullanııırken çatıda bölgenin yakınında yetişen bambu ve sazları kullanmıştır (URL-2,2021). Yapıda hem form hem de malzeme ve teknik ile geleneksel mimariye atıfta bulunulmuştur (Şekil1a-b). Diğer bir örnekte Uganda'nın güneybatısındaki Rakai, Mannya köyünde bulunan küçük bir toplum merkezidir. Ana yapı kil tuğla ile oluşturulurken; zeminde de kil karolar kullanılmıştır. Okaliptüs direkler ise kil tuğla duvarları taşıyıcı görevi üstlenmektedir. Yapıda ışığın mekâna alınması yerel mimariye benzer şekilde farkı açıklıklar ile; tuğlalar ve çatı arasındaki boşluklarla sağlanmaktadır (URL-3,2021). Yapı malzeme tercihi ve strüktür bağlamında yerel özellikler taşımakla birlikte özellikle ışığı mekâna alış biçimi ile algısal açıdan da ziyaretçilere farklı bir deneyim sunmaktadır 
(Şekil1c-d). Bangladeş'te tasarlanan, toprak ve bambunun yapı malzemesi olarak kullanıldığı okulda, zemin kat duvarlarında toprak malzeme işlenerek kullanılırken, üst katta yerel mimaride daha çok yapıyı yükseltmek ve ayakta tutmak amacıyla kullanılan bambu malzeme tercih edilmiştir (URL-4,2021). Yapıda yerel malzemelerin güncel anlayışlar ve iyileştirmeler ile kullanıldığı görülmektedir (Şekil1e-f).
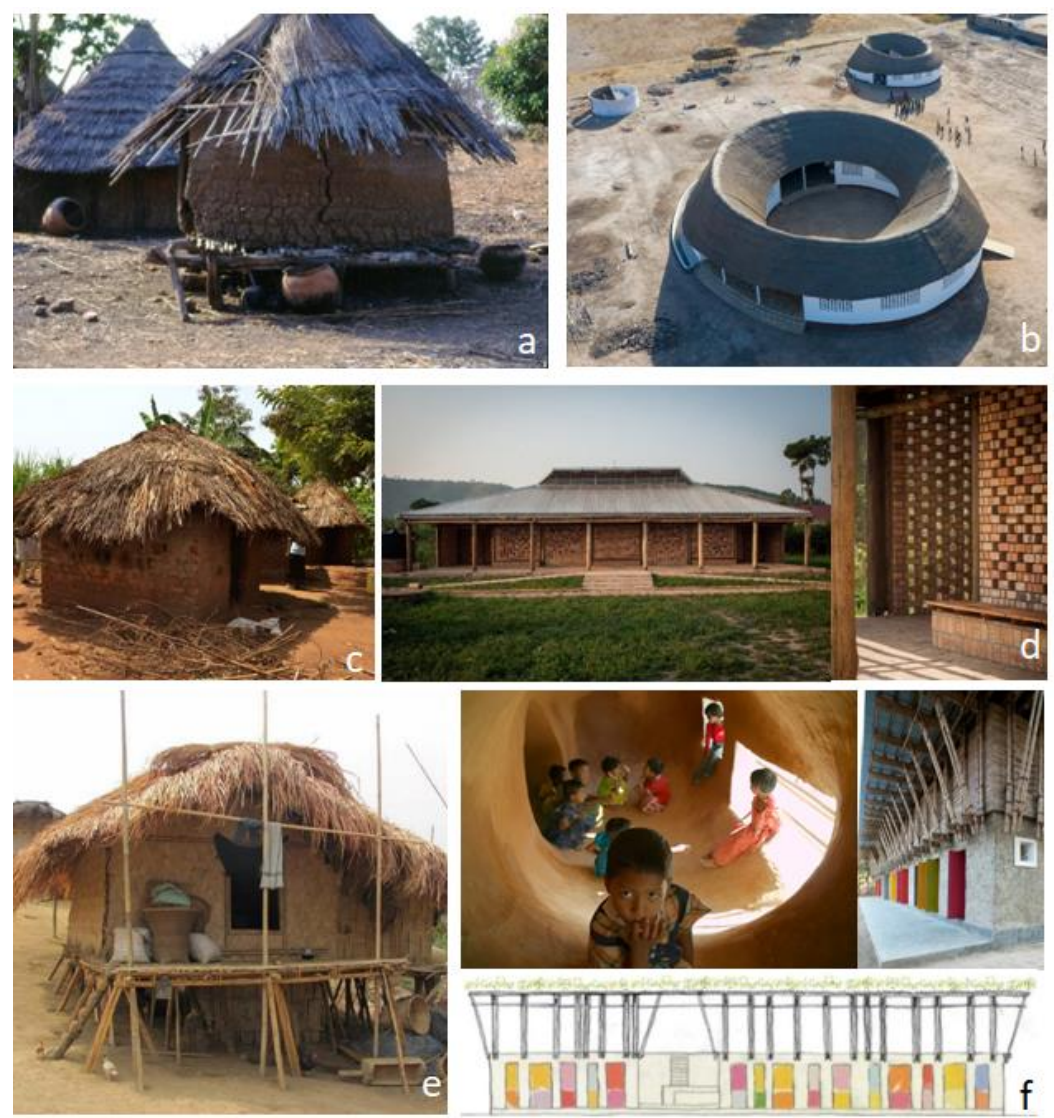

a. Geleneksel Senegal evleri (URL-5,2021); b.Fass Okulu (URL-2,2021); c.Uganda yerel mimari örneği (URL-6,2021); d. Sağlık Eğitim Merkezi (URL-3,2021); e. Bangladeş yerel mimari örneği

(URL-7,2021); f. Hand-Made School (URL-4,2021)

Şekil 1: Kerpiç ve tuğlanın kullanımı

Bir diğer yaygın malzeme türü olarak ağaç ise yetiştiği bölgenin özellikleri doğrultusunda çok farklı özelliklere sahip olabilmektedir. Her ağaç türü kendine özgü çeşitli özelliklere sahiptir ve bu özellikler; ağaç yaşı, genetik faktörler, yetiştiği bölge gibi değişkenlere bağlı olarak aynı ağaç çeşidinde dahi farklılık gösterebilmektedir (Doğu, 2016, s. 60). Yapı tasarımında da bambu, saz, çam, kestane gibi birçok ağaç türü ilkel veya gelişmiş yöntemlerle işlenerek ahşap malzeme elde edilmekte ve kullanılmaktadır. Organik bir malzeme olan ahşap biyolojik olarak dönüştürülebilir özelliğe sahiptir. Uzun ömürlü bir malzemedir ancak nem tutma özelliğine sahiptir. Bu nedenle de bölge koşulları doğrultusunda önlemler alınması gerekmektedir. Kullanılmadan önce yeterli bir şekilde kurutulmalıdır (Canan, 2003, s. 86). Bu gibi kriterler doğrultusunda hem geleneksel hem güncel yapılarda tercih edilmektedir. Örnekte, Warka Köyü, Tropikal yağmur ormanlarında izole bir toplum için gerçekleştirilen projede toprak, su, taş, odun ve doğal lifler gibi malzemeler kullanılmıştır. Bambudan yapılmış ve yerel yapım tekniği ile yapılmış 7 ev yer almaktadır (URL-9,2021). Projede düşük maliyet ve sürdürülebilir amaçlanmıştır (Şekil2). 

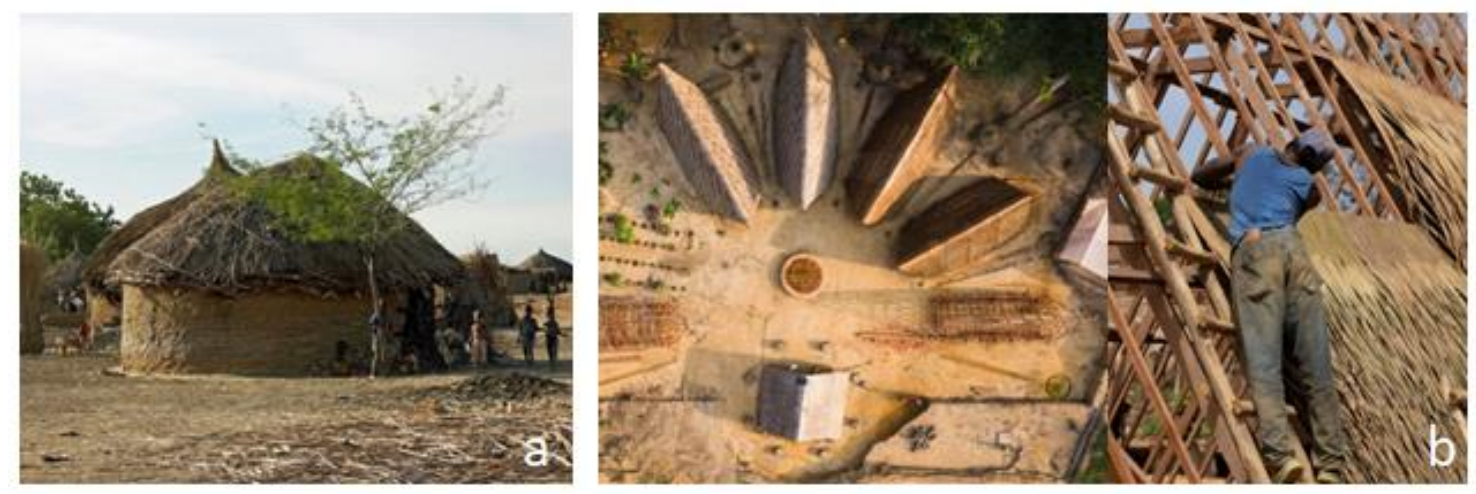

a. Kamerun'da yerel bir ev(URL-8,2021); b.Warka Köyü (URL-9,2021)

Şekil 2: Yerel Toprak, Su, Taş, Odun ve Doğal Liflerin Kullanımı

Taş malzemelerin ise yapı tasarımında çeşitli formlarda kullanıldığını görmek mümkündür. Taşıyıcı, kaplama, süsleme ve agrega olarak kullanımları bulunmaktadır (Erbaş, 2018, s. 30). Dayanımı ve buna bağıı olarak taşıyıcılık gibi özellikleri ile doğal taş malzemeler, büyük kütleler halinde veya parçalı olarak kullanılabilmektedirler. Yapının tasarlanacağı bölgede bulunan çeşitli doğal taşların işlendiği veya nehirlerden toplanan taş gabyonların kullanıldığı birçok güncel yapı örneği görmek mümkündür. Her malzeme türü kendi içinde çok sayıda çeşidi bulunmaktadır. Kullanım amaçları ve yerleri değişiklik gösterse de ulaşılabilirliği ve bölgesel şartlara uyum kabiliyeti nedeniyle yerel malzemeler geçmişten günümüze kullanıla gelmiştir.
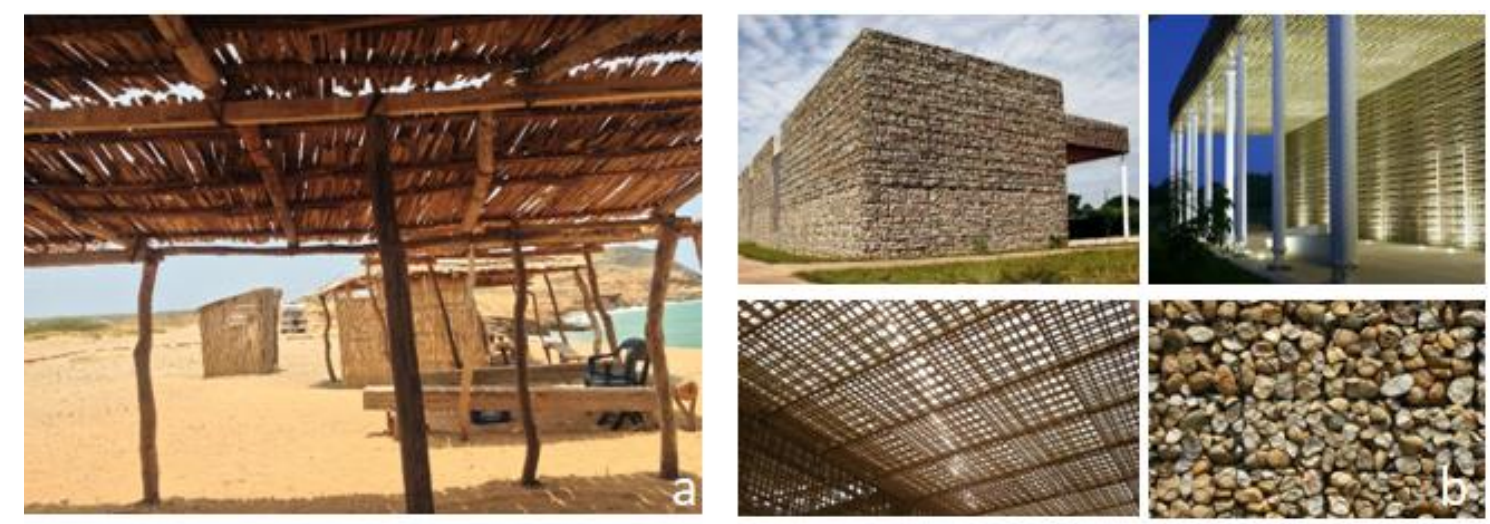

a. Kolombiya Yerel Mimari Örneği (URL-10,2021),

b. Villanueva Halk Kütüphanesi(URL-11,2021)

Şekil 3: Yerel Taş ve Ahşabın Kullanımı

Villanueva, Kolombiya'da 2006 yılında gerçekleştirilen kütüphane projesi örnek olarak verilebilir. Birçok radikal karar yer alan projede yerel ve ulaşılabilir malzemeler kullanılmıştır. Yakındaki bir nehirden alınarak oluşturulan taş gabyonlar, yapının cephe karakteristiğinde belirleyici bir rol üstlenmişlerdir. Çam ağacından üretilmiş ve üst örtü olarak kullanılmış plakalar hem dış hem de iç mekânda yapının algısını doğrudan etkilemiştir(URL-11,2021). Yapı; tasarım ve kullanılan malzemeler ile çevreye saygının ifadesi niteliğini üstlenirken, karakteristik ve yerel bir yapı izlenimi de vermektedir. Malzemenin uygulanış biçimi ile iç ve dış mekânda oluşturduğu doku ise yapıya çağdaş bir görünüm kazandırmıştır (Şekil3). 


\section{Tasarım ve Yerel Malzemenin Birlikteliği: Peter Zumthor}

$\mathrm{Bu}$ bölümde yerel malzemenin modern yaklaşımı ile ele alınmasında malzemeye yüklenen anlamın ne olduğu ve nasıl kullanıldığı üzerinde durulmaktadır. Bunun için yerel malzeme ve uygulamada yaratıcı düşünce sahip Peter Zumthor'un projeleri çalışma alanı olarak seçilmiştir. Zumthor, yalın çizgisi ve kendini tekrarlamayan tasarım anlayışına sahip İsviçreli bir mimardır. Meslek yaşamında birçok ödülün yanında, mimarlık alanın en önemli ödüllerden olan Pritzker Mimarlık Ödülü'nü 2009 yılında almıştır. Burada Zumthor için tasarladığı yapıların güçlü ve zamanın ötesinde olduğu, düşüncelerini şairane ölçülerle birleştirme yeteneğine sahip olduğu belirtilmiştir (URL12,2021). Zumthor ile ilgili malzeme kullanım şekli, moda-trendden uzak kendi üslubunun olması ve özel yetenekli olduğu vurgusu yapılmıştır (Yalçınkaya ve Açıcı, 2019 , s. 18). Malzemeyi ve detaylandırmada yaratıcı bir şekilde kullanan Zumthor, duyulara değmek ve dokunmak üzere tasarlanmış işleri merakla izlenen bir tasarımcıdır. Her defasında konuyu farklı şekillerde kurgulayabilmekte ve uygulayabilme gücüne sahiptir (Bilgin,2015,s.14). Birçok özgün projeye tasarlayan mimarın, yerel malzemeyi etkin kullandığı 5 yapısına incelenmiştir; Gugalun Evi, Benedict Şapeli, BruderKlaus, Şapeli İsviçre Pavyonu ve Termal Vals Kaplıcası yapılarında kullanılan yerel malzeme, mimari yaklaşım ve malzemenin bu noktada üstlendiği görev üzerinden değerlendirilmiştir.

Gugalun Evi (1994, Versam, İsviçre): İsviçre'de 1709'den kalma küçük bir ahşap kulübenin renovasyon projesidir. Mevcut dokuya eklemlenen "ek"ile ilgili bir tasarımdır. Tasarımın çıkış noktası mevcut yapıdaki geleneksel malzemenin yani ahşabın yüzeyidir. Eski ile yeni arasındaki ilişki malzeme üzerinde kurulmuştur. Yeni ekte, eskinin orijinal malzeme ve tekniğini kullanılmıştır. Bölgenin yapı geleneğinde yer alan geçmeli masif ahşap sistem, yeni ekte de kullanılmıştır. Yalnız uygulamada konstrüksiyonun üzeri kaplanmamıştır (URL-13,2021). Duvar ham bırakılırken, malzeme-ahşap- işlemden geçirilmiştir. Eskinin ile yeninin oluşturduğu kompozisyon ile zamanın sürekliliğini yansıtılmıştır. Mevcut kulübenin ahşabındaki eski hissi ile yeni ahşabın işlenmiş yüzeyi birbirlerini var eden bir görünüm oluşturmuştur (Şekil4).
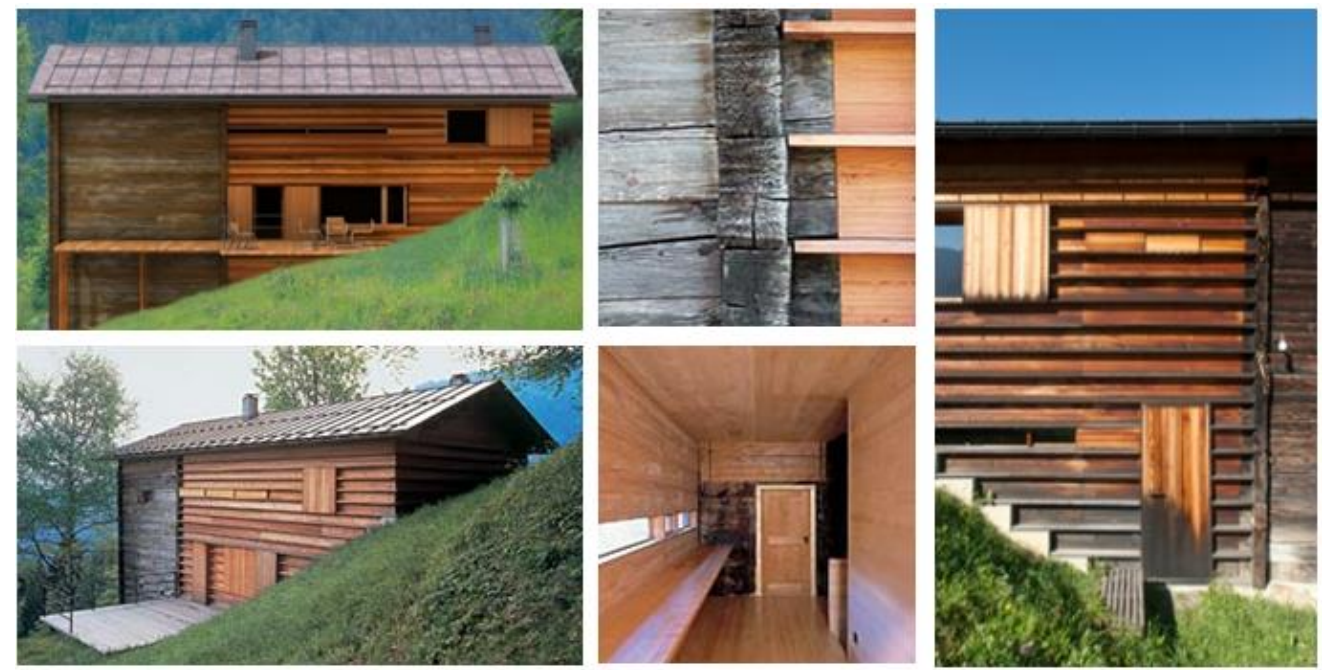

Şekil 4: Gugalun Evi ve malzemenin etkisi (URL-14;15,2021)

Benedict Şapeli (1988, Sumvitg,İsviçre):Yapının cephesinde İsviçre'de geleneksel yapılarda da sıklıkla kullanıldığı görülen "ahşap zonanın” kullanıldığı görülmektedir. Karaçam ağacından üretilmiş zonanın, yapının birleştirici karakterine katkı sağladığı 
düşünülmektedir (Vandenbulcke, 2011, s. 685). Ahşap zona, özellikle sert iklime sahip bölgelerde sıklıkla kullanılan; bu bağlamda kültürel açıdan büyük öneme sahip bir malzemedir (Kain vd., 2020, s. 16). Çatılarda sıklıkla kullanılmasıyla birlikte yapı cephesinde kullanıldığı örnekler de mevcuttur. Zumthor da ahşap zonayı yapının cephesinde kullanarak hem geleneksel yapı malzemesine gönderme yapmış hem de iklimsel bir intiyacı bu sayede karşılamıştır. Malzemeyi tasarım süreci içerisinde önemli bir noktada konumlandıran ve yerel malzeme kullanımını birçok yapısında tercih eden Zumthor'un yapısında malzemenin güncel bir anlayışla tasarıma uyarlandığı görülmektedir. Yapıda malzeme tercihi ile iklimsel koşullara dayanımın artırımasına ek olarak hem cephe hem iç mekânda malzeme yoluyla oluşturulan algı da Zumthor'un tasarım anlayışını ifade etmektedir (Şekil5).
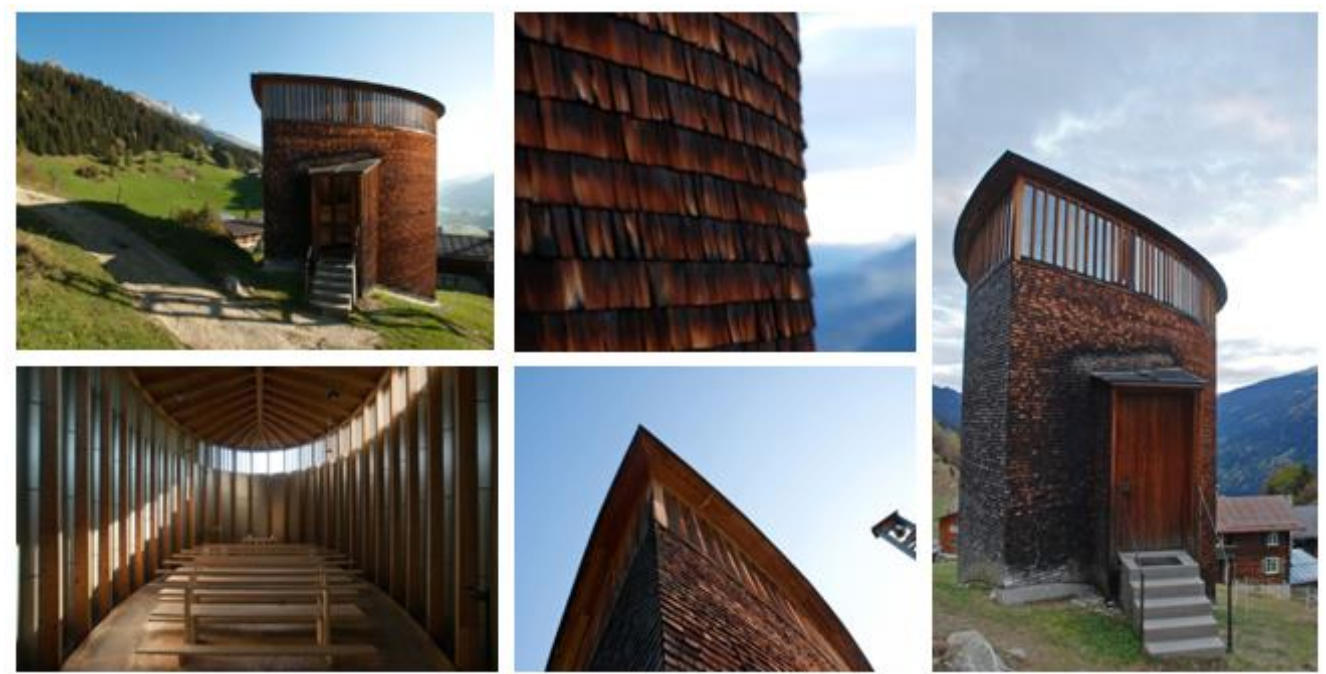

Şekil 5: Benedict Şapeli ve malzemenin etkisi (URL-14;16,2021)

Bruder Klaus Şapeli (2007, Wachendorf Köln, Almanya): Zumthor, bölgeye özgü malzeme ve teknikleri yorumlayarak, tasarımında özgünlüğü ortaya koymuştur. Malzeme olarak yerele ait nehir çakılı, Erp'teki Rhiem madeninden çıkartılan sarı kum, çam kütük ve beyaz çimento kullanmıştır (Yetim,2018, s. 46). Yapım yöntemi olarak kökü binlerce yı önceye dayanan arkaik bir imalat yöntemi kullanılmıştır. Zumthor, toprak kap yapma tekniğini yeniden yorumlamıştır. Yapının duvarları, ağaç dallarından oluşturulmuş iç iskeletin, dışında yer alan malzemenin kurumasından sonra yakılması ile oluşturulmuştur (Bilgin, 2015, s.96). Ortaya çıkan kütle, dışarıdan kum rengi bir görünüme sahipken, içeride yanan ahşabın oluşturduğu ağaç izi ve siyah doku hakimdir. İç mekânda ağacın yanması ile oluşan etki çok güçlüdür. Kalıpların sökülmesi ile ortaya çıkan boşlukların üfleme cam ile doldurulması yapıdaki her noktanın ince düşünülerek tasarlandığını ortaya koymaktadır (Şekil6). 


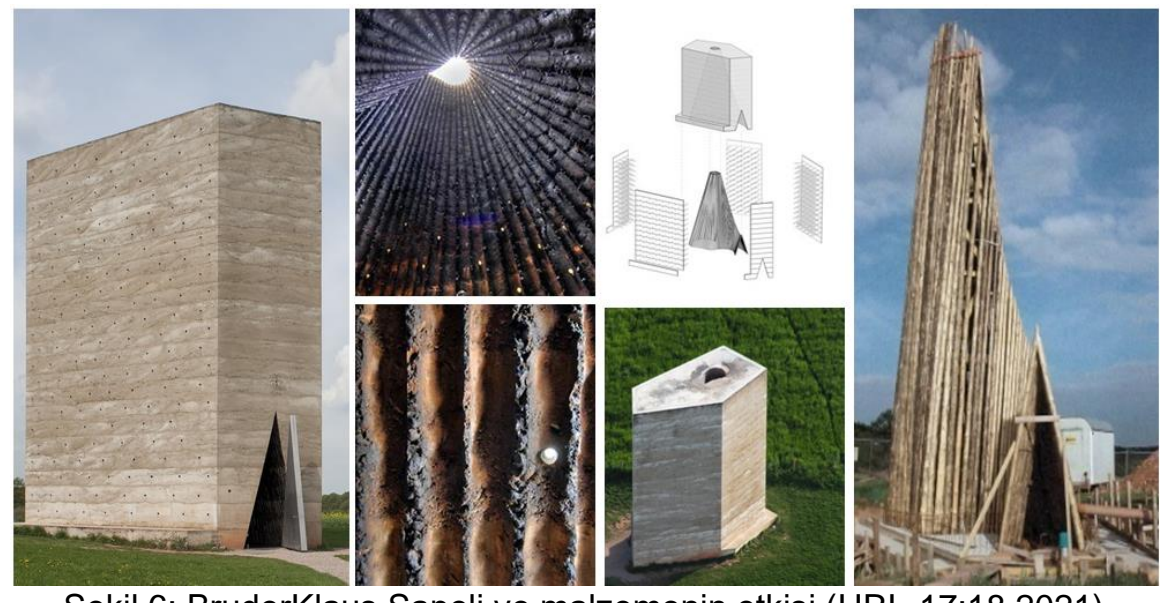

Şekil 6: BruderKlaus Şapeli ve malzemenin etkisi (URL-17;18,2021)

İsviçre Pavyonu (2000, Hannover, Almanya): Expo fuarı 2000'de İsviçre için tasarlanmış bir pavyondur. Düz anlamın kullanıldığı tasarım İsviçre'den taşınmış şeylerden oluşturulmuştur. İsviçre'nin Alp'lerinden ahşap getirilmiştir. Sürdürülebilirliğin benimsendiği tasarım anlayışında kalasların istiflenmesinden yararlanılmıştır. Duvarlar depo mantığından yola çıkılarak; çivi, vida, geçme vs. kullanılmadan, kalaslar arasında $5 \times 5 \mathrm{~cm}$ 'lik takozlar yerleştirilmesi ve çelik halatlarla sabitlenmiştir. $9 \mathrm{~m}$ yüksekliğinde 12 tane istif grubu oluşturulmuştur. 25 tane giriş-çıkışa sahip bir labirent oluşturulmuştur. 5 adet tını mekânı, sirkülasyon alanı ve servis alanlarından oluşan yapı, sökülebilir özellikte tasarlanmıştır. 448-290 cm arasında değişen $10 \times 20 \mathrm{~cm}$ kesite sahip 37.000 ahşap kalastan oluşmaktadır (Bilgin,2015, s.63) (Şekil7).
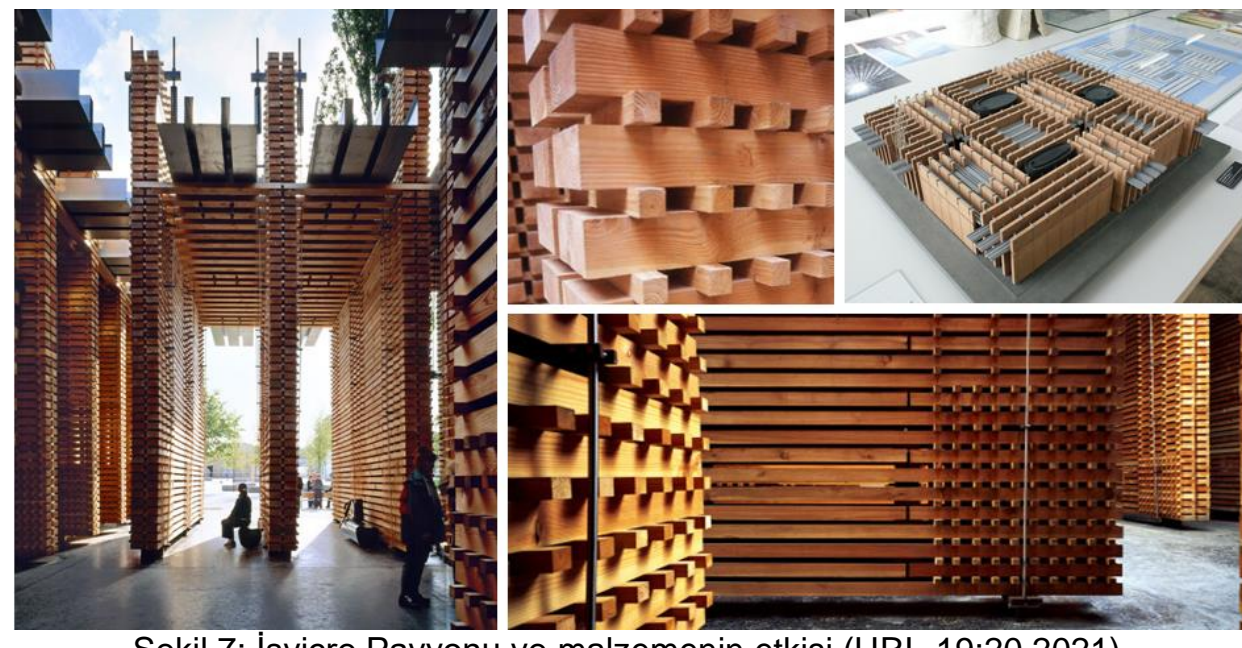

Şekil 7: İsviçre Pavyonu ve malzemenin etkisi (URL-19;20,2021)

Termal Vals Kaplıcası (1996, Vals, İsviçre):Yapı, İsviçre Alplerindeki Vals köyünde 1996 'da yapılmıştır. Kaynak suyunun işletilmesi amacı ile tasarlanan yapıda farklı sıcaklıklardaki buhar banyoları ve kaplıca havuzları ile özel bir kurgu oluşturulmuştur. Doğal çevreye uyumluluğun sağlamasında yapı belli ölçüde toprağa gömülmüş ve yeşil çatı örtüsü kullanılmıştır. Arazide akan sudan ve taş ocaklarından ilham alınmış ve bu birliktelik tüm binaya yayılmıştır. Yapının tasarımında bölgedeki taşocağından çıkarılan, yerel taş ürünü valser kuvarsitinden yapılmış levhalar kullanılmıştır. Duvarlar, taşların doğada bulunduğu haliyle tektonik katmanlar oluşturacak şekilde üst üste istiflenerek oluşturulmuştur (Bilgin,2015, s.15). Üç tip taş boyutu (31 mm, $47 \mathrm{~mm}$ ve $63 \mathrm{~mm}$ ) seçilerek oluşturulan $15 \mathrm{~cm}$ 
modülasyonun farklı şekillerdeki dizimi ile almaşık duvar yüzeyleri oluşturulmuştur (URL-21,2021). Duvarda yüzeyindeki bu kurallı kuralsızlık taş örgü sistemi ile doğadakine benzer bir doku elde edilmiştir (Şekil8).

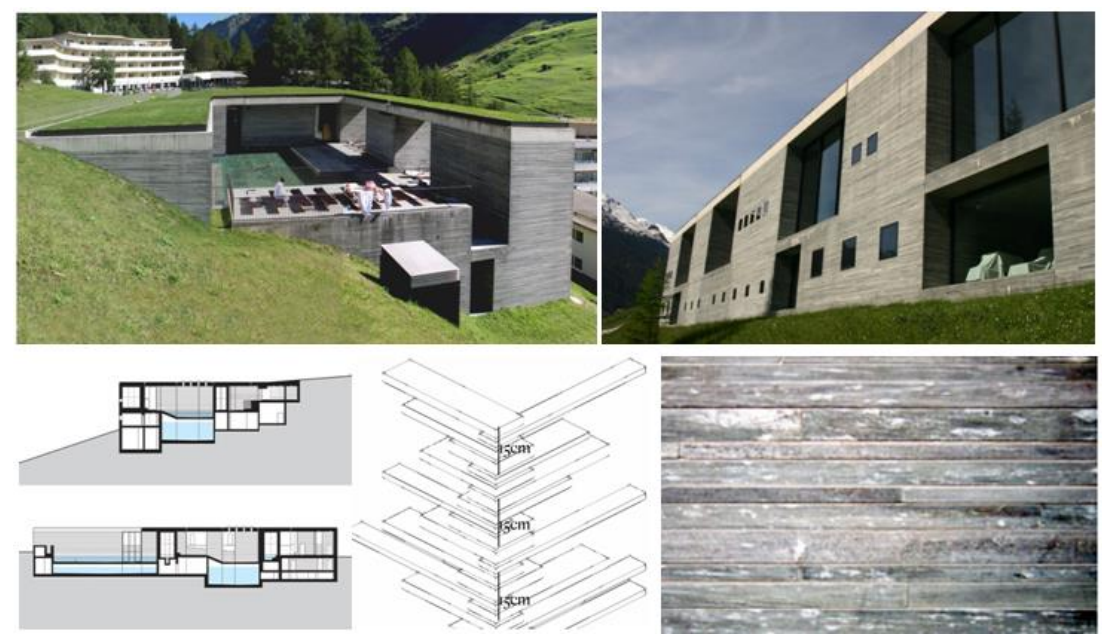

Şekil 8: Termal Vals Kaplıcası ve malzemenin etkisi (URL-21;22;23, 2021)

Zumthor tasarım anlayışı, yerel malzeme ve tekniklerin buluşması ile ortaya eşsiz yapılar çıkarmıştır. Mevcutta var olan herkesin gözü önündeki bu malzeme ve tekniklerin ustalıkla kullanımı mimarın sahip olduğu yeteneğin bir göstergesidir. Seçilen yapı örnekleri üzerinden değerlendirildiğinde, mimar tasarımlarında malzemeyi bir araç olarak kullanmaktadır. Tasarımda oluşturulmak istenin etki, malzeme ve uygulama tekniği ile sağlanmaktadır. Örneğin, Bruder Klaus Şapeli'nde "yaşanmışlığı” ve Gugalun Evin 'de "süreklilik" hissini verebilmek için tasarımda malzeme anlamsal bir amaç üstlenmiştir. Termal Vals Kaplıcası'nda "doğanın temsili" ve İsviçre Pavyonu'nda "sürdürülebilirlik" direk olarak malzemenin doğadaki şekli/ ham hali ile kullanılması ile malzeme tasarımda yansıtma amaçlı kullanılmıştır. Benedict Şapeli'de ise fiziksel konforun sağlanması (yalıım) amaçlı ve kültürel bir öğe olması nedeni ile malzemeden tasarımda hem işlevsel hem de anlamsal açıdan yararlanılmıştır (Şekil9). Diğer taraftan unutulmaya yüz tutmuş kaybolma tehlikesi ile karşı karşıya kalınan bu değerlerin-bilginin yaşatılması, kullanılması ile doğrudan ilişkilidir. Yerel malzeme ve tekniklerin mimari içerisinde bir şekilde var olmaya devam etmesini sağlamak, yeni gelişen teknoloji ve mimari görüşler ile bu bilgilerin buluşması ortaya özgün projelerin çıkabileceğinin göstermektedir.

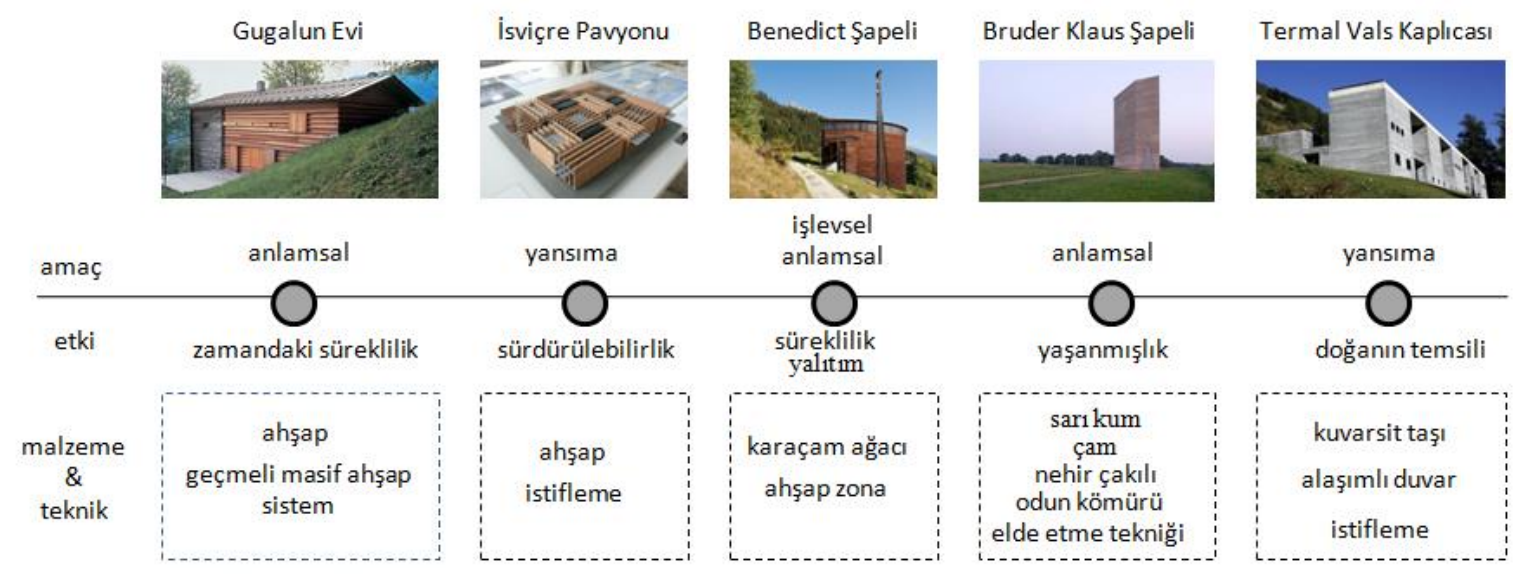

\section{Sonuç ve Değerlendirme}

Şekil 9: Peter Zumthor'un Tasarım Yaklaşımı ve Yerel Malzeme 
Güncel mimari tasarımlarda yerel malzemenin kullanım amacının incelendiği çalışmada, araştırma kapsamı Peter Zumthor'ın yerel malzeme kullandığı tasarıları ile sınırlandırılmıştır. Zumthor, yerel malzeme ve teknikleri kendi üslubuyla yorumlayarak kullanmıştır. 1968'de başladığı meslek yaşamında malzemenin özgün kullanımının görüldüğü eserler veren Zumthor'un bu çalışmada yerel malzemeyi kullandığı 5 yapısına yer verilmiştir. Her bir örnek farklı tasarım anlayışına sahip olmasına karşın yerel malzemenin özgün kullanımı noktasında benzerlik göstermektedir. Malzemenin yapıyı oluşturan fiziksel bir öğe olmanın ötesinde soyut bir düşüncenin somutlaştırma aracı olarak kullanıldığı görülmektedir. Zumthor dünyada sınırlı sayıda malzeme olmasına karşın malzemelerin bir araya getirilmesi ile oluşabilecek kompozisyonların sınırsız olduğu vurgusunu yapar (Zumthor, 2006, s. 6-73). Zumthor, tasarımlarında oluşturmak istediği atmosfere bağlı olarak, malzeme seçimini yapmaktadır. Örneklerde de görülmektedir ki yereldeki potansiyellerin tasarımda kullanılması, bugün tek tipleşen malzeme ve tekniğe karşı farklı bir bakış açısı kazandırmaktadır.

Yerel malzemenin kullanımı, yapının inşa edildiği bölgeyi temsil etmesi, o bölgeye ait duyguları barındırması, geçmişe yönelik çağrışımlar yapması ve farklı duyusal anlamlar yüklenmesi açısından önemlidir. Ayrıca sürdürülebilirlik, iklimsel ve fiziksel intiyaçları karşılama gibi farklı sebepler ile de tasarımlarda tercih edilebilmektedirler. Mimarların yerel malzemeleri tasarımlarında kullanma amaçlarından biride mimari kimlik yaratmak veya bölgedeki mevcut mimari kimliğe uyum sağlamak olduğunu göstermiştir. Her malzemenin kendine has bir karaktere sahip olduğu ve kullanımının farklı sonuçlar doğurabileceği bilinmekle birlikte araştırma sonuçları yerel malzemeye ait bilginin mimarlık pratiğinde kullanılmasının bilginin yaşatılması ve kimlikli, özgün yapılar ortaya konulması açısından önemli olduğunu göstermiştir.

\section{Kaynaklar}

Alaca Tınmaz, Özlem, Sürdürülebilirlik Değerlendirme Sistemleri Bağlamında Yerel Yapı Malzemesi Kullanımının İdelenmesi, Yüksek Lisans Tezi, Eskişehir Osmangazi Üniversitesi Fen Bilimleri Enstitüsü, Eskişehir2018.

Arpacıoğlu, Ümit ve Ayşegül Kuruç,"Zamansız Malzemelerin Zamanda Yolculuğu”, Mimarlıkta Malzeme Dergisi, 15, İstanbul 2010, s. 47-52.

Bilgin, İhsan,Mimarın Soluğu: Peter Zumthor Üzerine Denemeler, 1. B., Metis Yayınları, İstanbul 2016.

Canan, Fatih,"Sürdürülebilir Mimarlıkta Ahşap Yapı Malzemesi Kullanımı Lyss Orman Bekçiliği Okulu Örneği”, Yapı Dergisi, İstanbul 2003, (262), s. 85-91.

Çavuş, Murat, Dayı, Mustafa, Ulusu, Hayati ve Aruntaş, Yılmaz,"Sürdürülebilir Bir Yapı Malzemesi Olarak Kerpiç”, 2. Uluslararası Sürdürülebilir Yapılar Sempozyumu (ISBS), Ankara 2015, s. 184-192.

Doğu, A. Dilek, "Ahşabı Tanımak", Restorasyon ve Konservasyon Çalışmaları Dergisi, İstanbul 2016, (16), s. 59-71.

Dönmez, Esra, Türkiye'de Kültürel Kimliğin Mimariye Etkisi, Yüksek Lisans Tezi, Yıldız Teknik Üniversitesi Fen Bilimleri Enstitüsü, İstanbul 2006. 
Erbaş, İkbal, “Taş ve Taş Yapı Kültüründe Değişim ve Dönüşüm”, ATA Planlama ve Tasarım Dergisi, https://dergipark.org.tr/tr/pub/ataplanlamavetasarim 2018, 2(1), s. 2937.

Gezer, Hale,"Malzemenin Gizil Güçlerinin Mimariye Katkısı", İstanbul Ticaret Üniversitesi Fen Bilimleri Dergisi,https://ticaret.edu.tr/tr/Sayfa/Akademik/itud/itufbd22012, 20, s. 97-118.

Güzer, CelalAbdi,"Bir Sınır Sorunu Olarak Doğal ve Yapay”, Mimarlıkta Malzeme Dergisi,2, İstanbul 2006, s. 37-39.

Kain, Günther, Idam, Friedrich, Federspiel, Franz, Réh, Roman ve Krišt'ák,L'uboš, "Suitability of Wooden Shingles for Ventilated Roofs: An Evaluation of Ventilation Efficiency", Applied Sciences, https://www.mdpi.com/journal/applsci2020, 10 (18), s. 218.

Nooraddin, Hoshiar, "Architectural Identity in an Era of Change", Developing Country Studies,https://www.iiste.org/Journals/index.php/DCS2012, 2(10), s. 81-96.

Özgünler, Mustafa, "Kırsal Sürdürülebilirlik Bağlamında Geleneksel Köy Evlerinde Kullanılan Toprak Esaslı Yapı Malzemelerinin İncelenmesi", Süleyman Demirel Üniversitesi Mimarlık Bilimleri ve Uygulamaları Dergisi, https://dergipark.org.tr/tr/pub/mbud 2017, 2(2), s. 33-41.

Vandenbulcke, Benoît,"Concretion, Abstraction: The Place of Materialsin Architectural Design Processes. Case Study: Peter Zumthor", ARCC 2011 Considering Research: Reflecting Up on Current Themesin Architecture Research, Michigan 2011,s. 679-688.

Yağlı, Seçil,Teknolojik Gelişmelerin Etkisi ile Yüzeylerde Malzeme Kullanımı: Akıllı Malzemeler, Yüksek Lisans Tezi, Hacettepe Üniversitesi Güzel Sanatlar Enstitüsü, Ankara 2019.

Yalçınkaya, Şengül ve Kurak Açıcı, Funda,"Pritzker Mimarlık Ödülleri Ne Söylüyor",Akdeniz 2. Uygulamalı Bilimler Kongresi, Hatay 2019, s.13-26.

Yetim, Evşen, Mimarlıkta Atmosfer Kavramının Değerlendirilmesi: Zumthor Mimarlığı, Yüksek Lisans, Mimarlık Anabilim Dalı, Fen Bilimleri Enstitüsü, Karadeniz Teknik Üniversitesi, Trabzon 2018.

Yıldız, Bengi ve Seçkin, Nazire Papatya,"Mimaride Malzemelerin Algısal Farklılıklarının Değerlendirilmesi", Ístanbul Sabahattin Zaim Üniversitesi Fen Bilimleri Enstitüsü Dergisi, https://dergipark.org.tr/en/pub/izufbed 2019, 1(1), s. 6-14.

Zumthor, Peter, Atmospheres: Architectural Environments-Surrounding Objects, 5. B., Çev.: Iain Galbraith, Birkhauser, Berlin 2006.

Pamir, Haluk,“Mimari Tasarım Kurgusu: Malzeme”,XXI Mimarlık Kültürü Dergisi, İstanbul 2001, 7, s. 22-27.

\section{İnternet Kaynakları}


URL-1.Kengo Kuma, https://www.valextra.com/en-us/valextra-world/extravalextra/kengo-kuma-interview/(Erişim tarihi, 11.05.2021 saat:11.10)

URL-2.Fass Okulu, https://www.dezeen.com/2020/09/28/fass-school-thatch-senegaltoshiko-mori-architect/(Erişim tarihi, 12.05.2021 saat:12.50)

URL-3.Sağlık Eğitim Merkezi, https://www.archdaily.com/784113/health-educationcentre-ross-langdon-plus-studio-fh-architects(Erişim tarihi, 12.05.2021 saat:13.00)

URL-4.Hand-Made School, https://www.archdaily.com/51664/handmade-school-annaheringer-eike-roswag(Erişim tarihi, 12.05.2021 saat:13.15)

URL-5.Geleneksel Senegal Evleri,

http://www.africavernaculararchitecture.com/senegal/(Erişim tarihi, $\quad 12.05 .2021$ saat:13.30)

URL-6.Uganda Yerel Mimarisi, http://www.africavernaculararchitecture.com/uganda/ (Erişim tarihi, 12.05.2021 saat:13.40)

URL-7.Bangladeş Yerel Mimarisi https://www.re-thinkingthefuture.com/freshperspectives/a1634-vernacular-architecture-of-bangladesh/(Erişim tarihi, 12.05 .2021 saat:13.50)

URL-8.Kamerun Yerel Mimarisi, http://www.africavernaculararchitecture.com Igallery/cameroon/ (Erişim tarihi, 12.05.2021 saat:14.05)

URL-9.Warka Köyü,https://www.archdaily.com/946669/warka-water-and-arturo-vittoricreate-integrated-village-for-the-rainforest-community-in-cameroon(Erişim tarihi, 12.05.2021 saat:14.15)

URL-10.Kolombiya Yerel Mimarisi,https://howsthisarch.home.blog/2018/11/18/ vernacular-architecture-of-colombia-a-first-approach/(Erişim tarihi, $\quad 12.05 .2021$ saat:14.20)

URL-11.Villanueva Halk Kütüphanesi,https://www.archdaily.com/13853/villanueva \%25e2\%2580\%2599s-public-library-meza-pinol-ramirez-torres(Erişimtarihi, 12.05.2021 saat:14.30)

URL-12. Peter Zumthor, [erişim tarihi: 201920 Eylül]; https://www.pritzkerprize.com/ laureates/2009(Erişim tarihi, 20.09.2019 saat:12.00)

URL-13. Gugalun Evi, https://www.gzt.com/arkitekt/duyulara-hitap-eden-mimar-peterzumthor-3563817(Erişim tarihi, 09.05.2021 saat:17.30)

URL-14. Peter Zumthor,https://www.archdaily.com/419367/a-photographer-s-journeythrough-peter-zumthor-valley?ad_medium=gallery(Erişim tarihi, 09.05.2021 saat:15.30)

URL-15. Gugalun Evi, https://line.17qq.com/articles/nplhchndv_p6.html(Erişim tarihi, 09.05.2021 saat:17.00)

URL-16. Benedict Şapeli https://www.arkitektuel.com/saint-benedict-sapeli/(Erişim tarihi, 08.05.2021 saat:19.30) 
URL-17. BruderKlaus Şapeli, https://v3.arkitera.com/h17662-issiz-sadelik.html(Erişim tarihi, 10.05.2021 saat:12.10)

URL-18. BruderKlaus Şapeli, https://line.17qq.com/articles/ommhlppov.html(Erişim tarihi, 10.05.2021 saat:12.40)

URL-19. İsviçre Pavyonu, https://i.pinimg.com/originals/ad/a8/9b/ada89b2257797d330b8bb6b038d37dc5.png(Eri şim tarihi, 10.05.2021 saat:12.10)

URL-20. İsviçre Pavyonu, https://nickkahler.tumblr.com/post/92083054297(Erişim tarihi, 09.05.2021 saat: 10.15$)$

URL-21. Termal Vals Kaplıcası,https://xxi.com.tr/i/mimarligi-minorde-dusunmek(Erişim tarihi, 09.05.2021 saat: 12.05)

URL-22. Termal Vals Kaplıcası,https://pdfslide.net/reader/f/therme-vals-by-p-zumthorconceptual-approach-1(Erişim tarihi, 09.05.2021 saat: 12.25)

URL-23. Termal Vals Kaplıcası, https://www.architectural-review.com/buildings/thermalbaths-in-vals-switzerland-by-peter-zumthor(Erişim tarihi, 09.05.2021 saat: 13.00) 